\title{
THE USE OF MODERN SIMULATOR TECHNOLOGIES IN AIR TRAINING ON THE EXAMPLE OF THE AIR FORCE UNIVERSITY IN DĘBLIN
}

\author{
Henryk NOWAKOWSKI \\ Polish Air Force Academy, Dywizjonu 303 bl.12, 08-521 Dęblin, Republic of Poland \\ Jarosław KOZUBA \\ Silesian University of Technology, Faculty of Transport, ul. Krasińskiego 8, 40-019 Katowice, Poland \\ *Corresponding author. E-mail: h.nowakowski@law.mil.pl
}

\begin{abstract}
The article presents flight simulation training devices used for the training of students at Dęblin Air Force University from the early 60s until the present time. It includes information concerning the scope of the use of training devices in the teaching process as well as training itself of the university flying personnel. It also presents the development of flight simulation based on changes in the devices facilitating flight training, from training devices to the Integrated Training System. The use of flight simulators for the training of pilots is becoming an increasingly more important element of this training. More and more advanced flight simulators allow the implementation of the majority of flight procedures.
\end{abstract}

Keywords: training device; trainer; flight simulator; Integrated Training System

\section{INTRODUCTION}

The development of aviation technology creates the need to prepare properly trained aviation personnel to operate increasingly complex aircraft. The task of preparing aviation personnel is carried out by specialized aviation training centres, for example in the Military Aviation Academy in Dęblin. Currently, Dęblin University educates both military and civilian students on its premises. Officer cadets in the faculty of Aerospace Engineering, on the course of the aircraft pilot, undergo training in accordance with the specialization for jet pilots, transport aircraft pilots and helicopter pilots. When graduating from the university, they obtain their first university degree, a higher education graduation diploma as well as a professional pilot's licence. Moreover, they obtain a civil pilot's certification and licensing. The graduates of civilian studies in the faculty of Aerospace Engineering, on the course of the aircraft pilot, obtain their first university degree, a higher education graduation diploma as well as a civil pilot's licence on completion of the university. Owing to the implementation of the subjects which are required by the Aviation Law, included in the academic training programmes, and the practical implementation of aviation training, they are fully prepared to obtain the ATPL license.

The character of educating students at Dęblin University requires the use of a properly prepared logistics base, including aviation equipment, which meets the demands arising from the ongoing flight training. These include mainly airplanes, helicopters, as well as flight simulators and training devices. Flight simulators and training devices, thanks to their systematic enhancement, are becoming increasingly important in the process of flight training. This is reflected in the changes occurring in the aviation regulations, which define the rules on the use of flight simulators in flight training, changes in training programmes, but also mental changes with regard to the approach of pilots towards the exploitation of flight simulators in the training process.

\section{SIMULATORS USED AT THE AIR FORCE UNIVERSITY IN DĘBLIN}

The possibilities of using air equipment, available on the world market, for cadet training, were limited by geopolitical divisions after World War 2. 
Poland primarily operated aircraft equipment supplied by the Soviet Union, also including training devices. The University of Dęblin, in the 1960s, mostly used the "PCK-53" training device, the TE-1 (Figure 1) with the MiG-15 cockpit and the device for bomb practice called "UTB-3M" for the It-28 aircraft, in the air training of its military students.

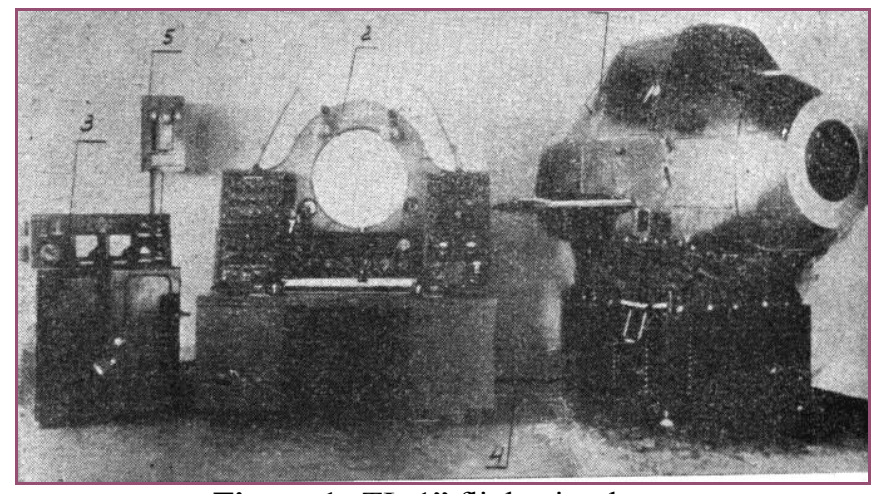

Figure 1 „,TŁ-1" flight simulator

Source: Air Force University archives

Between the 1960s and the 1980s, the "STL-2" cockpit, designed for the MiG-15 aircraft training, was used in air training. In 1964, the "TŁ-1" was replaced by its successor, an upgraded training cockpit, referred to as "TŁ-1M" (Figure 2), operated until 1990.

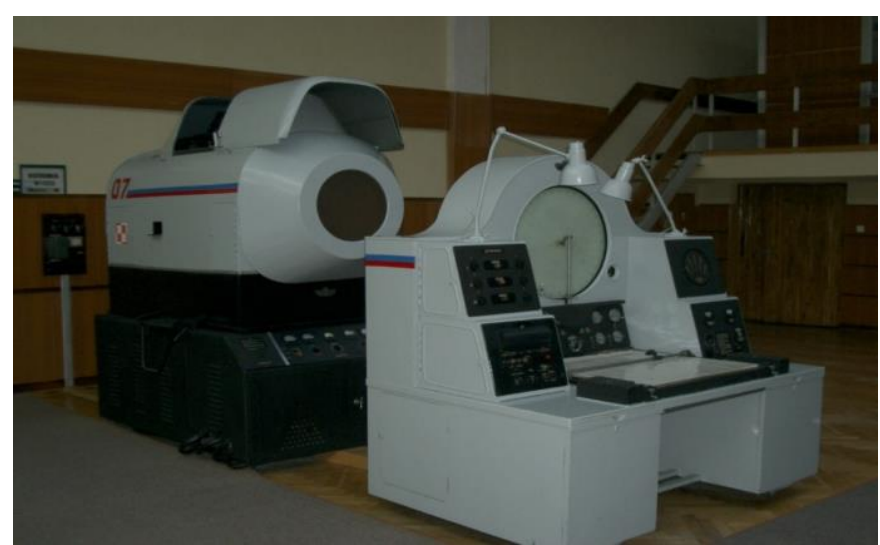

Figure 2 ,TŁ-1M” flight simulator

Source: Air Force University archives

The training cockpit"TŁ-1M" was used for training pilots and officer cadets who flew "Lim"-type aircraft, in all its versions and modifications. At a later period, when trainer aircraft TS-11 „ISKRA were introduced, the cockpit was adapted to the teaching and further practice of pilots performing flights on this airplane, as a „TŁ-1MI” version. The simulator provided an opportunity to learn and fly on instruments.

After some time, when new aircraft were purchased, also new KTS-type simulators were delivered. The KTS flight simulators were developed for the Mig-21, Yak-40, Mig-29, M-28 "Bryza" airplanes and the Mi-8 helicopter. Dęblin possessed the KTS-4 simulator for the MiG-21. The school also received the flight simulator for the $\mathrm{Su}-22$ aircraft. 


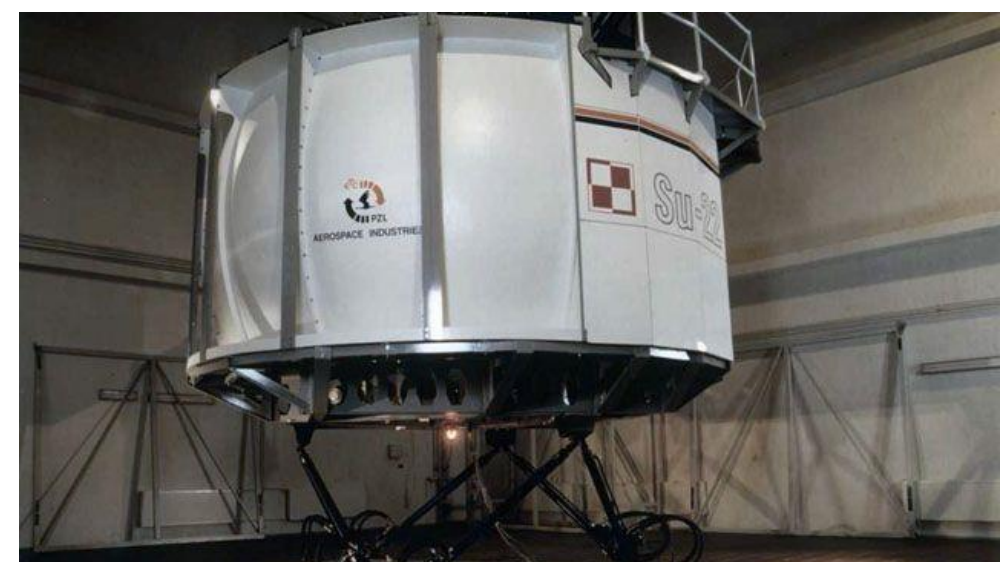

Figure 3 Su-22 flight simulator

Source: Air Force University archives

In the 1990s, the IDS-PZL Aerospace Industries designed and manufactured simulators for the TS-11 "Iskra", PZL-130 "Orlik", Su-22 M4 airplanes and also for the W3-WA "Sokół" helicopter, for the needs of the Polish Air Force.

In this way, new generation simulators and training devices appeared in the Eaglets' School of Dęblin. Pilots and military students flying the TS-11 "Iskra" may undergo trainings in an advanced "TS-Iskra" flight simulator (Figure 4). It is used to familiarize the cadets with the aircraft cockpit, learning and practising the operation of on-board equipment. The simulator teaches how to start the engine, how to taxi, perform takeoffs, flying patterns, fly military routes into the exercise area, land, fly on instruments, react in emergency and conduct radio correspondence.

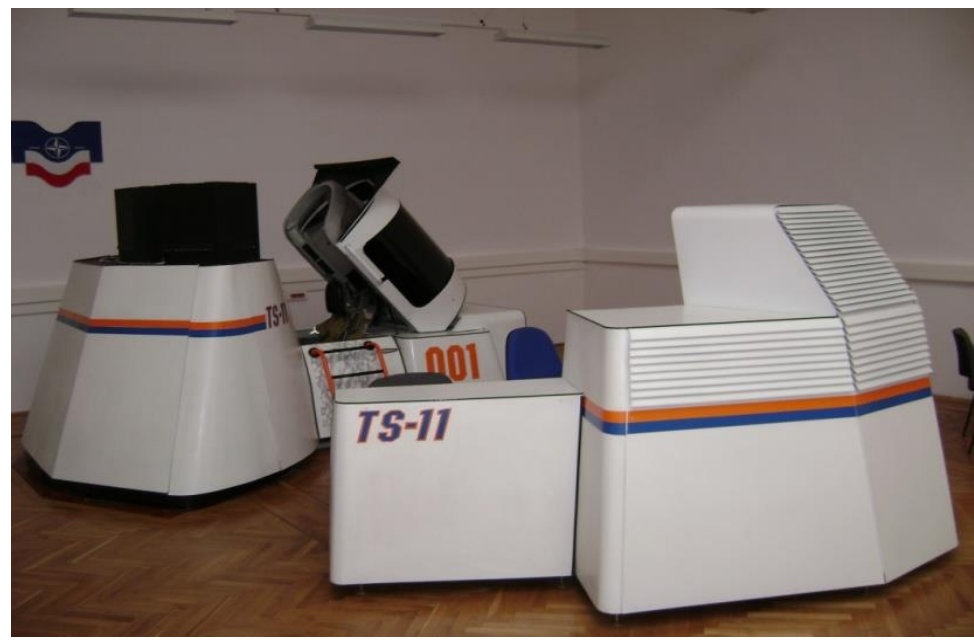

Figure 4 TS-11 „Iskra” flight simulator

Source: Air Force University archives

The flight simulator PZL-130 TC1 "Orlik" (Figure 5), similarly to the TS-11 "Iskra", is used to acquaint cadets with the cockpit, teach and practise the operation of on-board equipment, start the engine, conduct radio correspondence, conduct navigation in accordance with on-board instruments and ground-based radio navigation aids, navigate using the GPS, programme flight routes, taxi, take off and land, perform aerobatics, and conduct in the event of specific situations during a flight. The simulator enables the execution of the above-mentioned tasks, both by day and night in all weather conditions VFR/IFR. 


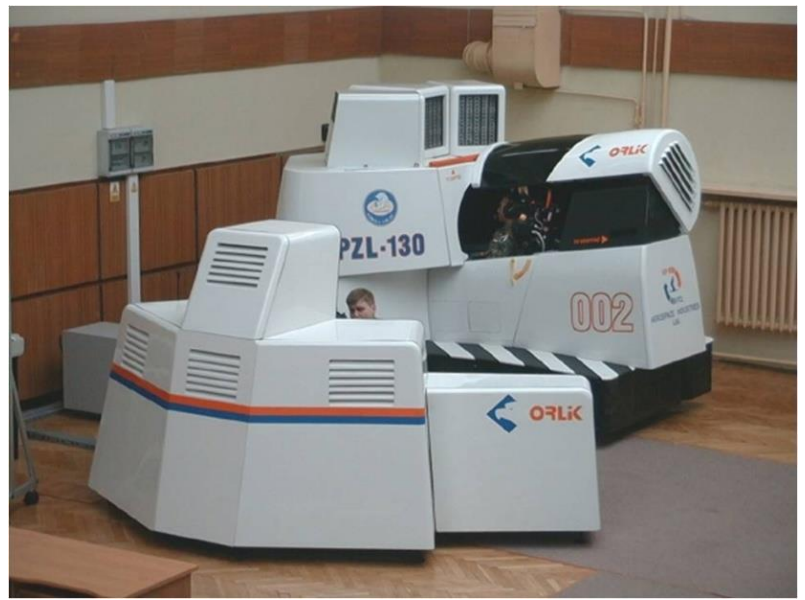

Figure 5 Flight simulator for PZL-130 TC1 „Orlik” Source: Air Force University archives

In the training of students, the ELITE Evolution S612 flight simulator is also used (Figure 6). It is a comprehensive and efficient computer flight simulator used in performing flights on instruments (IFR). The simulator reproduces the instrument panel, avionics and aerodynamics of the CESSNA172RG aircraft, allowing the users to practise all procedures and flight elements in different weather conditions, day or night. It gives an opportunity to practise procedures at different airports around the world. It also has the capability to monitor, record and recover the flight route as well as presenting it in the vertical and horizontal plane.
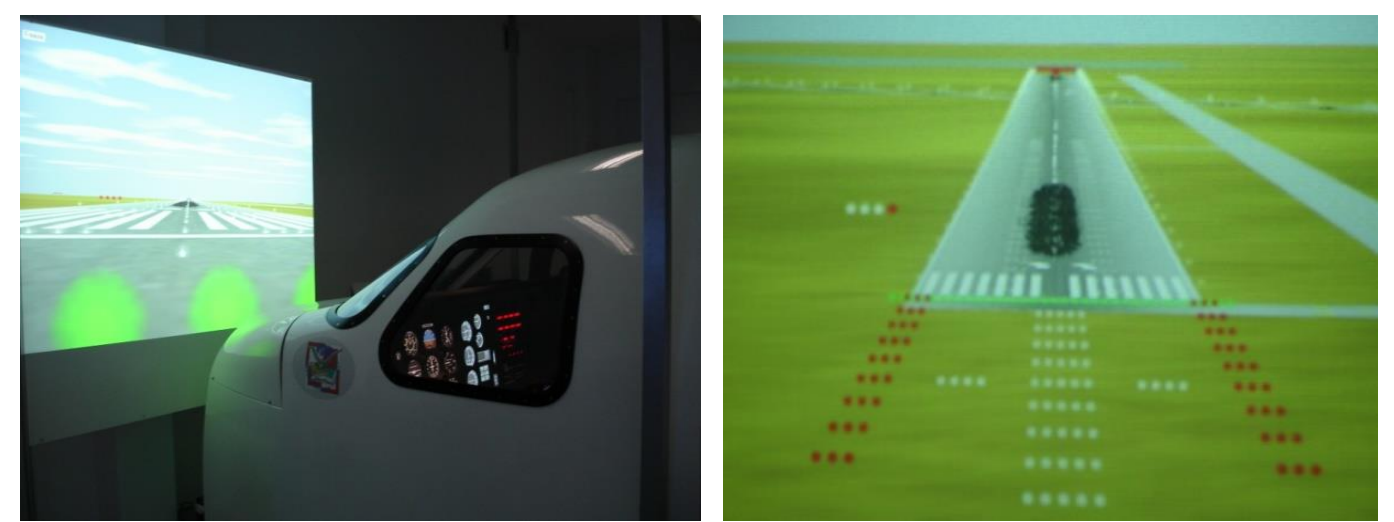

Figure 6 Flight simulator Elite Evolution S612 Source: Air Force University archives

In flight training, students also take advantage of such training devices as the ELITE PI-135 (Figure 7). They are used for the implementation of basic training on instruments. 


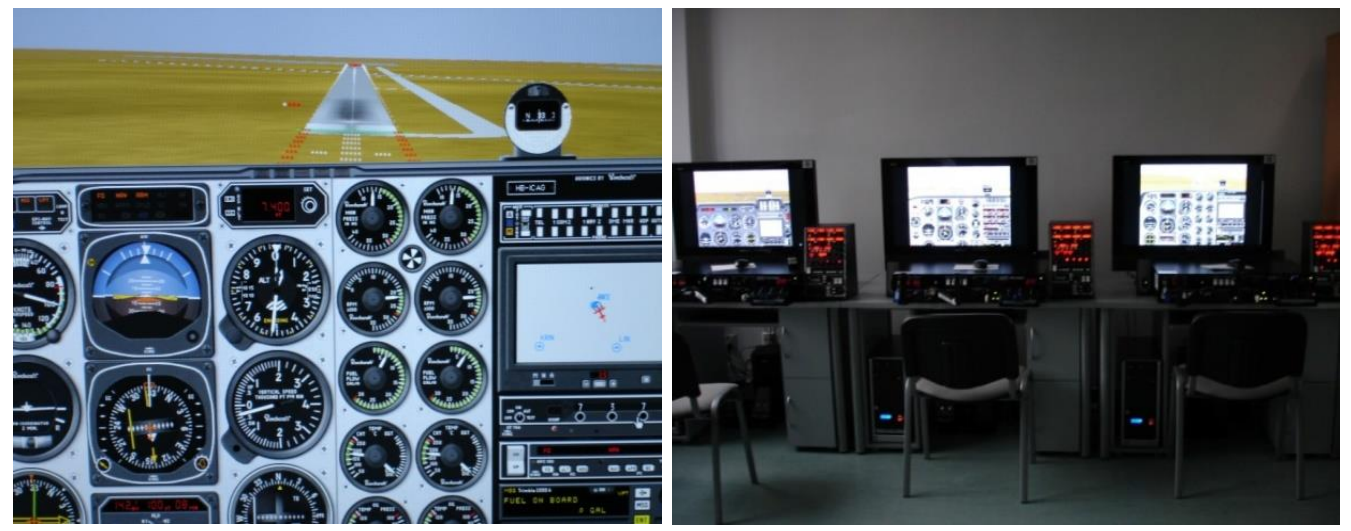

Figure 7 Flight simulator Elite PI-135

Source: Air Force University archives

Among training devices, used in the training of military students, there is also a flight simulator called "Selekcjoner", used for the selection of candidates for military pilots. It can be reconfigured to the W-3 „GLUSZEC" helicopter and F-16 aircraft cockpit. It is used for basic training, i.e. for becoming acquainted with the cockpit, learning and training how to operate the on-board equipment, start the engine, taxi, take off, land and conduct radio correspondence, navigate in accordance with onboard instrument systems and ground radio navigation aids as well as reacting to mid-air emergencies.

Also the simulator for the helicopter SW-4 "PUSZCZYK" (Figure 8), the helicopter "SCHWEIZER 300" and the light transport aircraft M-28 "BRYZA" (+MCC/ "SENECA", "CESSNA 172 RG") are used to practice take-offs, landings, flight manoeuvres and radio navigation. In these simulators, students practise flights with limited visibility, flights on instruments, as well as emergency procedures, under the supervision of instructors.

The cockpit is the central element of the simulators. It is surrounded by a large spherical screen, on which an image is displayed by a system of projectors. The visualization resembles flight conditions, being so realistic that the manoeuvres can "cheat the bony labyrinth", even causing nausea in the practising pilot, a condition which is likely to occur during a real flight.

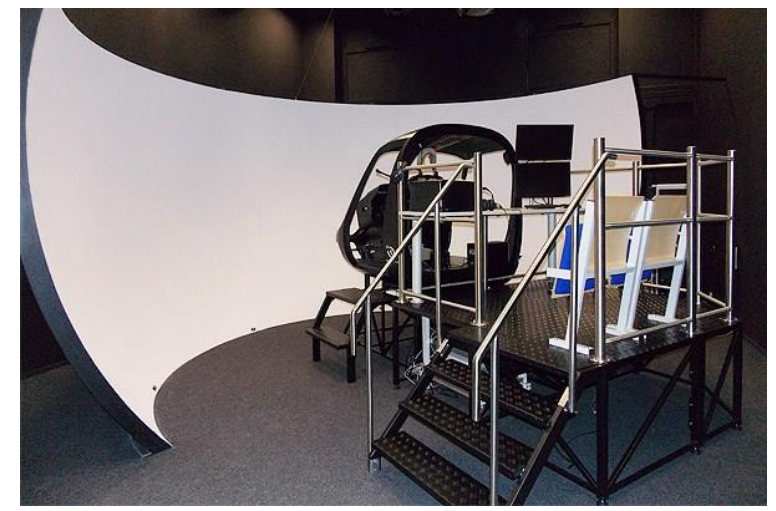

Figure 8 Flight simulator SW-4 „Puszczyk” helicopter Source: Air Force University archives

Currently, flight simulators in aviation training play a vitally important role. Therefore, most countries intending to purchase new aircraft types, during a tender, add a requirement to provide an appropriate class flight simulator, as part and parcel of the procurement.

This means that the manufacturer, apart from the aircraft, must submit an offer to provide a ground training system with adequate facilities. The expectations regarding training systems are constantly on the increase. Currently, the system should provide an opportunity to conduct integrated training, i.e. incorporate e-learning training, the use of a procedure simulator, an operational flight 
simulator, or a full mission simulator (FMS) (Figure 9), which ensures high realism of reflecting combat flight conditions.

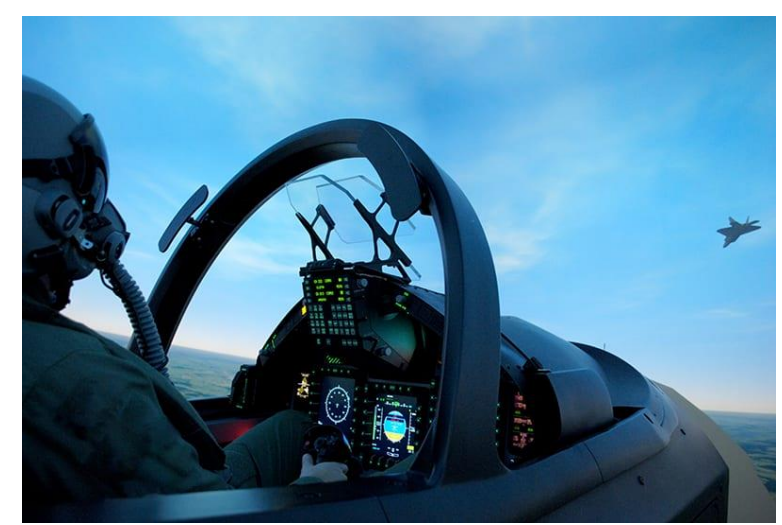

Figure 9 FMS simulator for the M-346

Source: https://militarysimulation.training/military-training/elbit-m-346-simulators-polish-air-force/

\section{NEW VIEWS ON FLIGHT TRAINING}

Due to the necessity of replacing the "TS-11 Iskra" in the training of military students with a newer generation aircraft which might meet the requirements of a modern approach to aviation training, it was decided to purchase the airplane M-346 Master, manufactured by Alenia Aermacchi. The contract included the procurement of aircraft with a complete training system (Integrated Training System - ITS). Apart from the aircraft, the Integrated Training System comprises a ground-based training system and appropriately integrated logistic support (Figure 10).

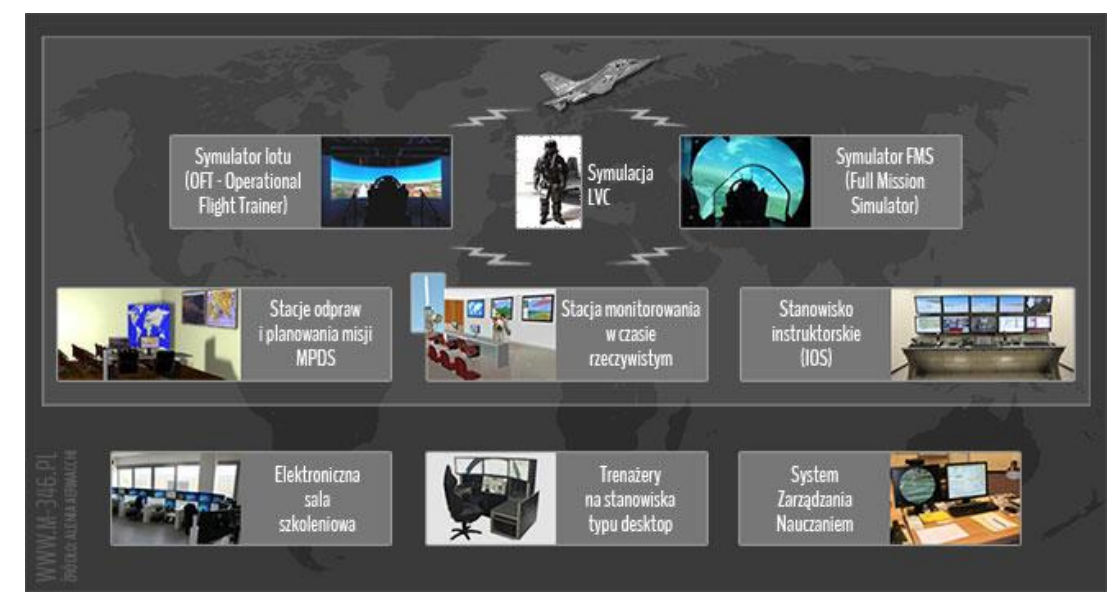

Figure 10 Components of ground training system

Source: https://militarysimulation.training/military-training/elbit-m-346-simulators-polish-air-force/

This system facilitates the implementation of aviation training from basic training to training in the execution of combat missions with a simulated use of weapons. Owing to a realistic simulation of the battlefield conditions, it is possible to practise offensive air-to-air and air-to-ground missions, or to apply defensive countermeasures.

A crucial ITS element is the ground training system. It gives an opportunity to couple the flight simulator with aircraft tactical simulation training, in-built in a real aircraft through data links. It allows the simulation of combat missions in a real flight. The pilot performing a flight can practise airto-air combat with a virtual opponent (i.e. an instructor performing a flight in a simulator in the role of an opponent). 
An important element of the system is the mission planning and debriefing station. Thanks to it, an instructor and a trainee pilot can plan tasks before a flight and on their completion, check and analyze the information recorded during the flight. It gives the trainee pilots an opportunity to learn and master the principles of planning and executing missions in real conditions on the required level.

The Embedded Tactical Training Simulation (ETTS) ${ }^{1}$ (Figure 11) is the quintessence of the whole integrated system of training. It offers a wide range of simulated scenarios of events.
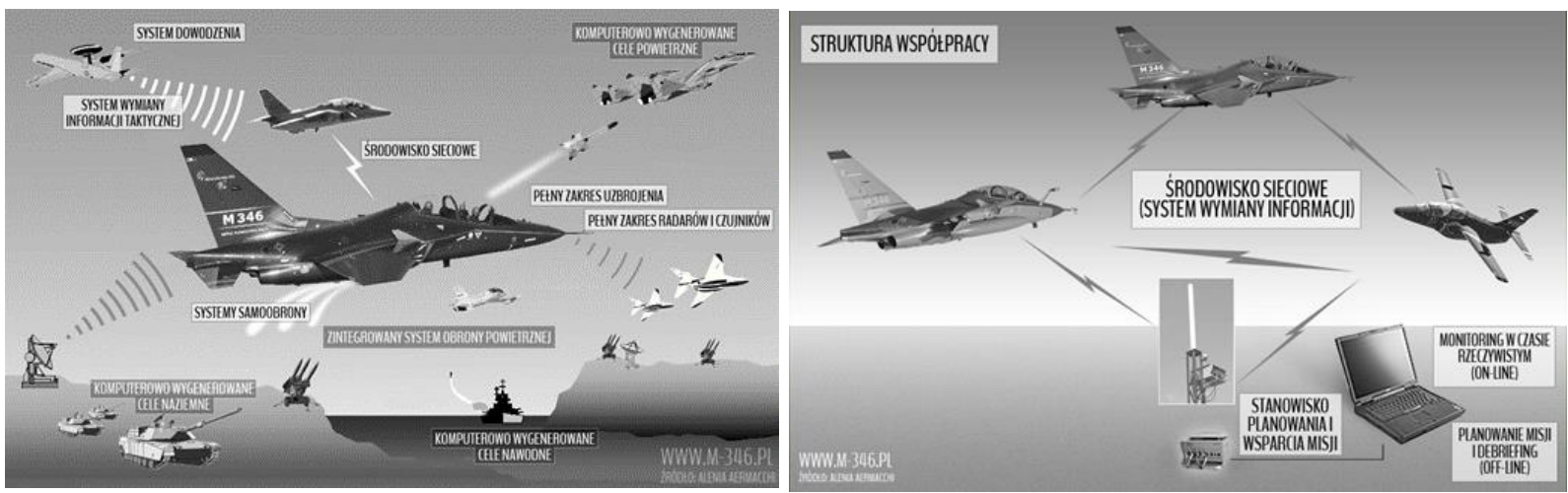

Figure 11 Embedded Tactical Training Simulation (ETTS)

Source: https://militarysimulation.training/military-training/elbit-m-346-simulators-polish-air-force/

It can simulate engagement of own or enemy forces during a mission, a simulation of various devices, for example radars and passive Electronic Warfare (EW) defence, and also a simulation of the use of weapons.

The system, while simulating a mission, is also capable of exchanging tactical information, using the multifunctionality of the on-board radar and exercising weapons handling.

The ITS system has the possibility of a reduction, or even a complete abandonment of using other aircraft in the training process, owing to computer-generated own forces and enemy forces. It gives an opportunity to plan not only single missions (using a single aircraft and one target), but also complex operations carried out by a larger number of aircraft, which are capable of maintaining full cooperation and data exchange between all elements.

\section{CONCLUSION}

The new flight simulation equipment, such as the Integrated Training System, is a new quality in the preparation of pilots for the tasks in the air. It allows limiting the cost of aviation training, but above all, it guarantees the safety of the learning process and practising procedures in difficult situations. Highly realistic simulation of flight conditions enables the students to learn and practise conduct in emergencies, as well as training complicated or dangerous manoeuvres in combat missions.

Looking on the possibilities of current flight simulation capabilities, it can be stated that an increasing part of the air training begins to be implemented with using flight simulators. Their planned use is included in aviation training programmes, where particular exercises are marked as to be performed in a simulator first. It means that the pilot, before sitting at the controls of the aircraft, must correctly perform a specific task in a flight simulator.

Direct linking of simulator training with practical training in the air, implemented due to the Integrated System of Training, also significantly increases the effectiveness of the training. The pilot instructor has received additional tools which allow him a more comfortable conduct of the training.

\footnotetext{
${ }^{1}$ ETTS (Embedded Tactical Training Simulation)
} 


\section{References}

[1] Kulik T, Bogusz D. “Symulatory w szkoleniu lotniczym” Przegląd Sił Zbrojnych no 4/2014

[2] Barszcz P, Wesołowski M. Blacha K. „Sterowanie procesem szkolenia na symulatorach lotniczych w oparciu o charakteryzujące go wartości” Prace naukowe ITWL zeszyt 37, pp.7394, Warszawa 2015

[3] Szczepański C. „Symulatory lotu w ostatnim 60-leciu” - Mechanika w lotnictwie Volume I, Warszawa 2012

[4] Kralewski P. "Pozyskanie systemu szkolenia zaawansowanego AJT odmieni polskie lotnictwo szkolne". [In English: "Acquiring an advanced AJT training system will change Polish aviation education".] Available at: http://Dlapilota.pl. 2014.

[5] Seminar Proceedings for Simulators in Aviation: New Technologies. Warsaw, Dęblin 2008

[6] Elbit Systems delivers M-346 simulators to Polish Air Force. Hampshire: Military Simulation \& Training (MS\&T) magazine. Available at: https://militarysimulation.training/militarytraining/elbit-m-346-simulators-polish-air-force/

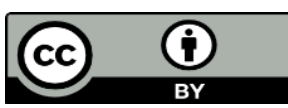

Article is licensed under a Creative Commons Attribution 4.0 International License 